\title{
Q-I/IIA-OS formula for predicting left atrial pressure in mitral stenosis
}

\author{
Ömer Yiğitbaşi, İstemi Nalbantgil, Ahmet Birand, and Ahmet Terek \\ From the Department of Medicine, University of Ege, School of Medicine, Izmir, Turkey
}

The relation of the phonocardiographic time intervals (Q-I) and (IIA-OS) and the use of two formulas ( $Q-I, I I A-O S$ difference versus their ratio) for estimation of left atrial pressure were investigated in 70 cases of pure mitral stenosis.

It was noted that, in cases with normal blood pressure and pulse rate, there was a fair correlation of the two intervals to left atrial pressure. In our studies the best correlation was obtained by using the ratio of these two intervals $(Q-I) /(I I A-O S)$.

These results indicate that it is possible to use a new formula and equation that are dependable for phonocardiographic evaluation of left atrial pressure.

The classical auscultation findings of mitral stenosis were described as 'roûffou-ta-ta' in 1862 by Duroziez. In this description roûffou indicated the diastolic rumble and the loud first heart sound, ta-ta the splitting of the second heart sound. However, the latter was reinterpreteted as the second heart sound followed by the opening snap of the mitral valve. Rouchès (I888) used the statement of 'claquement d'ouverture de la mitrale' for the first time. It was shown later that there was no constant relation between the severity of stenosis and the intensity of the rumble.

Subsequently, two phonocardiographic time intervals were widely used to evaluate the severity of mitral stenosis. These are: (a) the time interval between the onset of the QRS complex of the electrocardiogram and the onset of the first heart sound (Q-I interval), and (b) the time interval between the aortic component of the second heart sound and the mitral opening snap (IIA-OS interval).

The Q-I interval is usually prolonged in mitral stenosis. However, there is a discrepancy between different workers about this correlation (Wells, 1954; Kelly, 1955; Craige, 1957; Proctor et al., 1958).

The IIA-OS interval is usually decreased in mitral stenosis but the degree of this aberration is discussed by various authors (Wells, 1954; Kelly, 1955; Rich, 1959; Di Bartolo, Núñez-Dey, and Bendezú-Prieto, 1962).

Received 3 December 1969.
Davies (1967) disagreed with the degree of changes of the Q-I and IIA-OS intervals but stated that the figure obtained from the difference between them is useful in determining left atrial pressure.

In this study, we investigated the correlation of the two above-mentioned time intervals and Davies's formula in 70 cases of pure mitral stenosis. For the first time we used the formula Q-I/IIA-OS for measuring left atrial pressure.

\section{Subjects and methods}

Seventy patients ( 42 female, 28 male) with mitral stenosis were studied, whose ages ranged from 16 to 48 years.

The diagnosis in these patients was confirmed by right and left heart catheterizations. Left atrial pressure was obtained by using Radner's (1955) suprasternal puncture technique. The phonocardiograms were recorded by means of a Sanborn Twin-Beam machine. The heart rate of these patients, both during catheterization and during the recording of the phonocardiogram, varied between 70 and 90 a minute. Patients with atrial fibrillation were studied only if they had a ventricular rate ranging from 70 to 90 a minute. The systolic blood pressures of the patients were between 150 and $100 \mathrm{~mm} . \mathrm{Hg}$.

\section{Results}

Left atrial pressures were in the range of II to $40 \mathrm{~mm} . \mathrm{Hg}$, an average of $25 \pm 9 \mathrm{~mm} . \mathrm{Hg}$.

The Q-I time interval varied between 0.06 and $0.1 \mathrm{I}$ sec., with a mean value of $0.08 \pm$ 0.03 sec. The coefficient of correlation (r) 


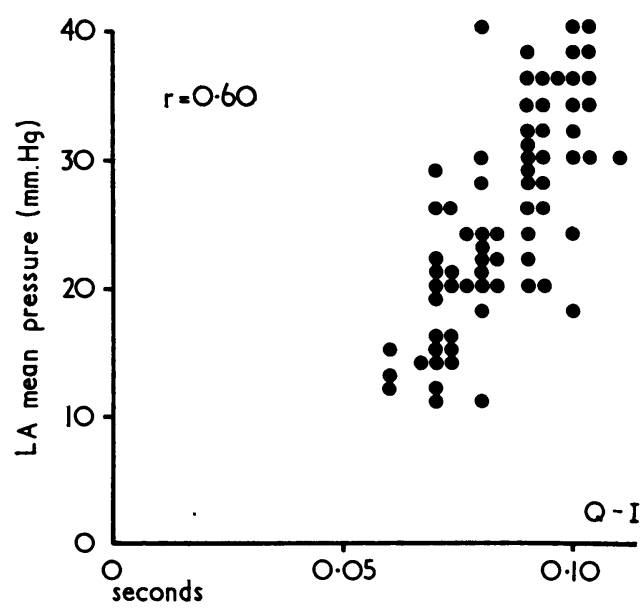

FIG. I The relation between left atrial mean pressure and $Q-I$ interval. There is a rough correlation. The coefficient of correlation $(r)$ is 0.60 .

between the Q-I interval and left atrial pressure was $+0.60 \quad(t=6.186 ; p<0.01)$. The calculated regression equation was: $L A=$ 180(Q-I) + 10.6 (Fig. I).

The IIA-OS intervals were in the range of 0.04 to 0.10 sec., with an average of $0.07 \pm$ 0.03 sec. The coefficient of correlation between the IIA-OS and left atrial pressure was $-0.55(t=5.431 ; p<0.01)$. The calculated regression equation was: $\mathrm{LA}=-165$ (IIA-OS) +36.55 (Fig. 2).

The formula (Q-I) - (IIA-OS) ranged from -0.04 sec. to 0.06 sec., with a mean value of $0.02 \pm 0.02$ sec. By using this formula, the

FIG. 2 The relation between left atrial mean pressure and IIA-OS interval. There is a rough correlation. The coefficient of correlation $(r)$ is -0.55 .

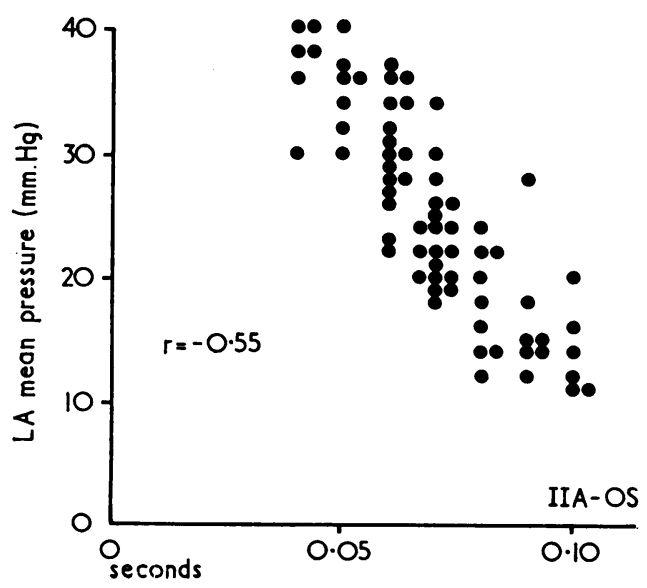

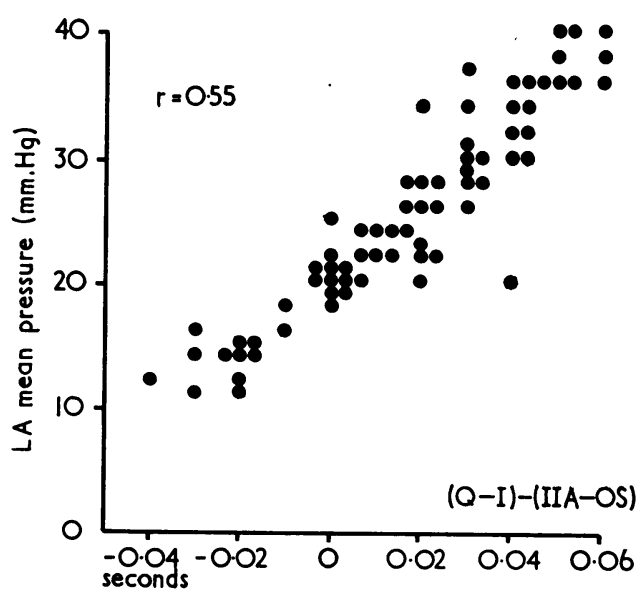

FIG. 3 The relation between left atrial mean pressure and $(Q-I)-(I I A-O S)$ formula.

There is also a rough correlation. This formula is not superior to the other two intervals. The coefficient of correlation of this formula is equal to the coefficient of correlation of the IIA-OS interval.

coefficient of correlation (r) was found to be $0.55(t=5.431 ; p<0.01)$. The regression equation was: $\mathrm{LA}=8 \mathrm{I} 8(\mathrm{Q}-\mathrm{I})-(\mathrm{IIA}-\mathrm{OS})+5.4$ (Fig. 3).

The (Q-I)/(IIA-OS) ratio ranged from 0.06 to $2 \cdot 50$, with a mean value of $\mathrm{I} \cdot 33 \pm 0.46$. The coefficient of correlation was +0.91 using the above formula ( $t=18.100 ; p<0.001)$. The calculated regression equation was: $\mathrm{LA}=$ I7·8O(Q-I)/(IIA-OS) + I.33 (Fig. 4).

FIG. 4 The relation between left atrial mean pressure and Q-I/IIA-OS formula. There is a good correlation between them. This formula is better than others. The coefficient of correlation is 0.91 .

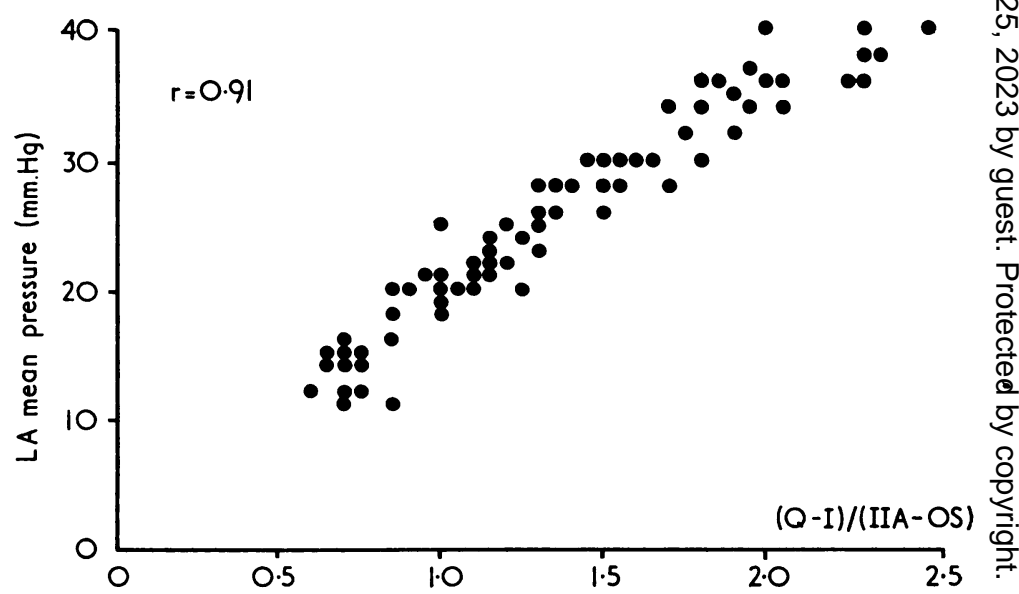




\section{Discussion}

The Q-I interval corresponds to the time between the onset of the QRS complex of the electrocardiogram and the first heart sound.

* It is necessary for left ventricular pressure to exceed the left atrial pressure for the closure of the mitral valve. A delayed closure seems to influence the occurrence of the first heart sound. The Q-I interval is prolonged in systemic hypertension (Weissler, Leonard, and Warren, 1958), persistent ductus arteriosus, tetralogy of Fallot with shunt operation, atrial septal defect with right-to-left shunt (Karnegis and Wang, 1963, 1966) as well as in mitral stenosis. In cases with atrial fibrillation and rapid ventricular response, the Q-I inter$\mathrm{val}$ is longer than in cases with slow ventricular response.

In normal subjects, it is difficult to hear the opening snap of the atrioventricular valves. However, an opening sound has been recorded phonocardiographically in a number of normal subjects. The opening of the mitral valve can take place only when the left atrial pressure is greater than the left ventricular. Thus, - IIA-OS interval indicates the isometric relaxation period, i.e. the period between closure of the aortic valve and opening of the mitral valve even though the sound phenomena occur slightly after the valve events. This interval is usually decreased in mitral stenosis. However, it is also decreased in patients with systemic hypertension, mitral insufficiency, aortic stenosis and insufficiency (Leo and Hultgren, 1959; Rich, 1959; Oriol et al., 1965). In patients with atrial fibrillation and slow ventricular response, this interval is longer than in patients with rapid ventricular response (Messer et al., 1951).

The correlation between the Q-I and IIA-OS intervals and left atrial pressure has been investigated by several workers. Our studies are in agreement with the above workers. We preferred to select patients with normal heart rates and normal systolic pressures in order to avoid complicating factors. All our patients were selected after exclusion of aortic valve lesions and of mitral insufficiency. We noticed that the above precautions were not followed by some workers whose results were less satisfactory than those of others.

Davies (1967) was unable to establish a good correlation between the Q-I, IIA-OS intervals and left atrial pressure. However, he recognized that the factor obtained from the difference between Q-I and IIA-OS (Q-I)(IIA-OS) was directly related to left atrial pressure. In contrast, our study did not show any greater significance of this difference over the two intervals per se. Moreover, Davies' formula is applicable only to patients with normal heart rates.

We then came to the conclusion that a new formula (Q-I)/(IIA-OS) was superior to the others as revealed by a statistical study ( $r=$ $0.91 ; t=18.100 ; p<0.001)$. It has the advantage of being applicable to cases with a wide range of heart rates because it is based on a ratio instead of subtraction of the two intervals. Therefore, we recommend this formula for the phonocardiographic evaluation of the left atrial pressure because of high dependability and accuracy. The calculated regression equation for this formula is as follows:

mean LA pressure ( $\mathrm{mm} . \mathrm{Hg}$ )

$$
=\mathbf{I} 7 \cdot 80(\mathrm{Q}-\mathrm{I}) /(\mathrm{IIA}-\mathrm{OS})+\mathrm{I} \cdot 33 \text {. }
$$

\section{References}

Craige, E. (1957). Phonocardiographic studies in mitral stenosis. New England fournal of Medicine, 257, 650 .

Davies, J. P. H. (1967). A simple phonocardiographic formula for predicting left atrial pressure in mitral stenosis. British Heart fournal, 29, 843.

Di Bartolo, G., Núñez-Dey, D., and Bendezú-Prieto, J. (1962). Left heart studies in mitral stenosis with special reference to intracardiac phonocardiography. American fournal of Cardiology, 10, 93.

Duroziez, P. (1862). Essai sur les maladies du coeur; du rhythme pathognomonique du rétrécissement mitral. Archives Générales de Médecine, ser. 5, 20, 385.

Karnegis, J. N., and Wang, Y. (1963). The Q-I interval of the phonocardiogram in patients with ventricular septal defect, patent ductus arteriosus and Blalock anastomosis. American fournal of Cardiology, 11, 452.

$\longrightarrow$, and 1 (1966). Q-I interval of the phonocardiogram in patients with atrial septal defect. British Heart fournal, 28, 240.

Kelly, J. J., Jr. (1955). Diagnostic value of phonocardiography in mitral stenosis. American fournal of Medicine, 19, 862.

Leo, T., and Hultgren, H. (1959). Phonocardiographic characteristic of tight mitral stenosis. Medicine, 38, 85.

Messer, A. L., Counihan, T. B., Rappaport, M. B., and Sprague, H. B. (195I). The effect of cycle length on the time of occurrence of the first heart sound and the opening snap in mitral stenosis. Circulation, 4, 576.

Oriol, A., Palmer, W. H., Nakhjavan, F., and McGregor, M. (1965). Prediction of left atrial pressure from the second sound-opening snap interval. American fournal of Cardiology, 16, 184 .

Proctor, M. H., Walker, R. P., Hancock, E. W., and Abelmann, W. H. (1958). The phonocardiogram in mitral valvular disease. American fournal of Medicine, 24, 861.

Radner, S. (1955). Extended suprasternal puncture technique. Acta Medica Scandinavica, 15I, 223. 
Rich, C. B. (1959). The relationship of heart sounds to left atrial pressure. Canadian Medical Association Fournal, 8I, 800 .

Rouchès, F. J. M. (1888). Du claquement d'ouverture de la mitrale, étude clinique, séméiologique et pathogénique. Thesis, Paris.
Weissler, A. M., Leonard, J. J., and Warren, J. V. (I958). Observations on the delayed first heart sound in mitral stenosis and hypertension. Circulation, 18, 165.

Wells, B. (1954). The assessment of mitral stenosis by phonocardiography. British Heart fournal, 16, $26 \mathrm{I}$. 